\title{
Tracking the Objects of the Psychopathology On Interdisciplinarity of Psychopathology on the Margins of Historia polskiego szaleństwa
}

\author{
Przemysław R. Nowakowski \\ Institute of Philosophy and Sociology \\ Polish Academy of Sciences, Warsaw, Poland \\ pnowakowski@ifispan.waw.pl
}

Received 1 March 2019; accepted 21 July 2019; published 12 December 2019

\begin{abstract}
This paper is a loose commentary on Marcinów's book (2017). The commentary is focused on the objects of psychopathological investigations and the role of psychology / psychiatry tension in the process of singling out, tracking, and describing them. As a consequence, there are limitations of collaborative and integrative efforts between psychologists and psychiatrists where questions of psychopathology are concerned.
\end{abstract}

Keywords: Mira Marcinów; psychopathology; history of psychology; history of psychiatry; biography of psychological objects; interdisciplinarity.

\section{Introduction}

Marcinów's (2017) book is a very rich and comprehensive attempt to capture the history and sources of psychopathology based on Polish nineteenth-century works. Now, the first volume of the announced trilogy is available, dedicated to melancholy. Marcinów focuses on the formation of Polish melancholy terminology and the distinctively Polish approach of melancholy both in scientific research and in art or culture more generally. The book consists of three, rather distinctive, parts. The first one contains introductory, theoretical considerations accompanied by a rich historical analysis. The second one contains an extremely broad variety of historical resources (which, I believe, can be re-used in the future, in many interesting textual studies on the history of Polish psychiatry). The third one contains paintings, pictures, and photographs related to issues from first part of the book. 
Here, I will focus on the first part of Marcinów’s book. Even the shortest and most general outline of the Marcinów's (2017) investigation directs our attention to two general issues. First of all, it is the birth or construction of terminology, and classification of mental problems in general. ${ }^{1}$ In Marcinów's work, the formation of psychopathological terminology related to melancholy is studied in the works of Polish researchers and physicians. The second issue is the very nature of psychopathological research itself. This will be my starting point and main topic for my comments on Marcinów work. As Berrios (1984) noticed: "[t]he history of psychopathology [...] is a powerful calibration technique by means of which the language of psychiatry is conceptually tightened and made ready for quantification" (p. 310) and "[...] collaborative work between psychiatric clinicians and historians is urgently needed and suggests as the first common task the calibration of descriptive psychopathology" (p. 303). Therefore, Marcinów's research on the birth of Polish psychopathology should be an excellent opportunity to calibrate our (Polish) psychopathological dictionaries. But maybe it could also add a little Polish contribution to the psychopathological knowledge in general.

In what follows, I focus on an unsolved tension hidden in the treatment of a psychopathology and its objects by Marcinów. This is the tension between psychological and psychiatric approaches to psychopathology.

A few words of explanation. Here, I assume roughly but uncontroversially that psychiatry and psychology are different disciplines with different, sometimes entangled, histories or biographies (Danziger, 1993, 2003), terminologies, methods and objects of research. Psychology is a behavioral science focused on human behavioral performances in the intraindividual and inter-individual variability context, whereas psychiatry is a medical specialty, mostly focused on mental malfunctioning investigated in case or cohort studies. While psychology is mainly focused on psychological effects, the psychiatry is focused on symptoms. These differences have changed in history and possibly at the beginning of scientific psychology, the differences between psychology and psychiatry were elusive and hard to track. However, when properly investigated, they could be very fruitful for research on interaction between both disciplines.

Without any doubt, this is a naïve and rough picture, and it's possible to make more nuanced distinctions, including relations between particular schools, traditions, or approaches in psychology and psychiatry. Taking that into account, some of them are closer to each other (e.g., a narrative psychiatrist and a humanistic psychologist), and some are not related at all (RDoC proponents and psychologists form psychodynamic traditions). However, I believe that even a more nuanced approach to the issue will not be in conflict with my argumentation.

It is so because I only want to argue that psychopathology is a peculiar area of investigation, where psychology (especially the clinical one) and psychiatry start to collide and merge. The mentioned differences can be helpful but sometimes also harmful. Therefore,

\footnotetext{
${ }^{1}$ Marcinów seems mostly interested in history of terms (Sierra \& Berrios, 1997, p. 214).
} 
we should proceed even more carefully when focusing only on one of psychopathological disciplines, in Marcinów case on the psychological part of psychopathological history or biography (Danziger, 1993, 2003). If we neglect the distinction between the psychological and psychiatric aspects of psychopathological research, then we cannot say that we are talking about psychological part of the story. However, this is a minor issue. A more pressing problem is that we risk losing sight of the fact of emergence issues related to the psychological or the psychiatric way of conducting psychopathological research. Some of these issues will be described later in the paper.

There is a quite extensive literature on birth of scientific psychology (Brock, Louw, \& van Hoorn, 2006; Danziger, 1993, 1994, 2013) and the maturing of psychiatry in the $19^{\text {th }}$ century, and they are quite independent at that time in Europe (mainly France, Germany and UK) and the USA (Berrios, 1984, 1988, 1996, 2008; Mora, 1970; Sierra \& Berrios, 1997). There are even some studies of the conflict between these two in the context of research on mental pathology (Blustein, 1981; Clark, 1981). Therefore, looking on these issues in the context of Polish research could be very informative. However, which is a little disappointing, Marcinów did not take up this thread in her work.

It's possible to develop this commentary in two ways. On the one hand, one could focus on historical issues and present tensions in then research. On the other hand, one could show why the issue of tension between psychology and psychiatry is so important. I chose not to present any detailed historical or any similar analysis of development from the $19^{\text {th }}$ century to contemporary psychopathology. There is no place for such a project in a short commentary such as this one. I focus on showing possible repercussions of neglecting these issues even in history-oriented reconstructions. I will try to look on issues discussed by Marcinów through the lenses of contemporary studies on interdisciplinary research. ${ }^{2}$

In the first part, I present rough remarks on interdisciplinary research. In the second part, I focus on Marcinów's remarks on the birth of Polish psychopathology and psychopathology in general as having psychological or rather medical origins. Here, I will elaborate on the issue of ambiguity presented in Marcinów's work (2017). In the third part, I will discuss some problems, mainly interdisciplinary ones in the case of psychopathology. In the fourth part, I will summarize the whole commentary.

\footnotetext{
${ }^{2}$ Here, I will not propose any exhaustive account of interdisciplinarity of scientific research. However, for the sake of clarity, I propose to draw a general distinction between: (a) multidisciplinary research, as conducted by representatives of different disciplines, but without interaction, coordination and integration between these studies; (b) interdisciplinary research, where we can observe interactions, coordination or integration between different disciplines; (c) transdisciplinary research, where interactions, coordination or integration involve stakeholders that do not represent traditional research disciplines (e.g. artists, industry representatives, NGO's, or local communities; Boden, 1999; Grüne-Yanoff, 2016; Klein, 2010; Koskinen \& Mäki, 2016).
} 


\section{From Interdisciplinary Research to Psychopathology}

As we mentioned, in psychopathological research, psychology and psychiatry start to collide or merge. We can say even stronger that psychopathological studies, historical and contemporary, are (or at least should be) interdisciplinary, where psychiatrists, psychologists, neuroscientists, and even philosophers or ethicists cooperate (see: Campaner, 2014). Therefore, if we want to separate one thread and focus on, for example, the psychological aspect of psychopathology, we should be cautious in disentangling it, because it easy to conflate threads from biographies of different disciplines. Although Marcinów rightly recognizes the complexity of psychopathological research, she does not notice its highly interdisciplinary character, i.e., its disciplinary diversity and its consequences.

Furthermore, contemporary literature is increasingly pointing to the plurality and diversity of psychopathological research. It is becoming more and more common to take a pluralistic position (see: Campaner, 2014; Van Bouwel, 2014; Zachar, 2012). ${ }^{3}$ And although this pluralism itself is not necessarily related to the disciplinary diversity and vice versa, it seems that the possibility that this pluralism is the result of differences between disciplines involved in studying psychopathology is worth considering. In particular, Campaner (2014) points out, among various sources of pluralism in psychiatry, "a plurality of disciplinary fields involved" (p. 91).

There will be kind of disciplinary pluralism, where different disciplines can come with different epistemological, methodological, or practical standards. However, the differences can go deeper. Borsboom with collaborators (2009), following Cronbach (1957), points to a significant methodological discrepancy between the two approaches to psychological research: experimental vs. correlative. Of course, this conflict is rather intradisciplinary, not interdisciplinary, but if one of disciplines is challenged by such conflict, then it is highly probable that an interdiscipline containing this discipline will also face these problems even in a higher degree.

My commentary on Marcinów's book will begin from directing attention to research on the interdisciplinarity. I am convinced that this will allow us to see an important, albeit unnoticed, aspect of her research.

\subsection{Some Issues Disclosed by Interdisciplinary Studies}

We must introduce some issues of interdisciplinary studies, if we want to show how they could help in our (and Marcinów) endeavor. Interdisciplinary studies, as I mentioned earlier, focus on the conditions of interdisciplinary cooperation, the formation of interdisciplinary research teams, as well as the evaluation, and implementation of interdisciplinary research projects. One of the basic aspects of this research is the analysis of issues that

\footnotetext{
${ }^{3}$ Marcinów could argue that even if contemporary psychopathology/psychiatry is interdisciplinary, her analysis was historical. Different replies to this argument are possible. For example, we can say that this interdisciplinary pluralism is an intrinsic feature of psychiatry, as determined by the complex and diverse character of its problems.
} 
limit of the cooperation between stakeholders form different research disciplines. Such obstacles could arise from different reasons. Showing these differences can be very helpful for understanding the specificity of each discipline involved in interdisciplinary research, and its actual role in this project.

There are not only obvious differences in theories and subjects of research, or methods used in different disciplines. Most often, less explicit sources of conflicts are indicated. For example:

a. different approaches to what is considered as data and to what is considered proper ways of collecting and using these data;

b. divergent attitudes toward theoretical research, its role and importance;

c. various epistemic standards (e.g., validity and reliability procedures and results);

d. different daily practices, habits, routines;

e. various repertoires: material, behavioral social and cultural components of research (Ankeny \& Leonelli, 2016; Leonelli \& Ankeny, 2015) and different experimental protocols (Sullivan, 2009);

f. difference in the scope of the disciplinary field (Peterson, 2016, 2017);

g. different significance of ethical and social issues in the conducted research.

These differences could be further multiplied. It will be informative to consider psychology vs. psychiatry interaction/divergences in psychopathology, and even in a broader perspective, the research of the mental in general.

If my reading of Marcinów (2017) is correct, she insists that the history of psychopathology - in particular, the case of melancholy - is the part of the history of psychology. Therefore, using Danziger's terminology, the biography of melancholy should be considered as part of the biography of psychology (Danziger, 1993, 2003). However, without seeing simultaneous theoretical and also institutional development of Polish psychology as a scientific discipline and without seeing its further development in the $20^{\text {th }}$ century (Marcinów focused only on the $19^{\text {th }}$ century), the picture seems to be a little patchy and blurry. This picture could be more problematic as it seems, if we-for example-looked on research developed in the psychoanalytical tradition, especially on the involvement of the psychoanalytic movement in development of the $20^{\text {th }}$ century psychiatric research (until the formation of DSM-III, in particular). ${ }^{4}$

Here, I limit myself to more general issue, in order to shed some light on tensions between psychiatry and psychology in the case of psychopathology. So, we can go back to the issue of interdisciplinary research.

\footnotetext{
${ }^{4}$ Moreover, exposing not only the issue of melancholy but also the intricacies of methodological and institutional background of development of Polish psychiatry could help in Marcinów's project, as it seems, which is the development of a comprehensive approach to the Polish way of living melancholy.
} 


\subsection{From Interdisciplinary to Psychopathological Studies}

In the literature, we can find an interesting and informative analysis of problems encountered by cooperating economists and ecologists (Armsworth, Gaston, Hanley, \& Ruffell, 2009; MacLeod \& Nagatsu, 2018) as well as systemic and molecular biologists (MacLeod, 2018; MacLeod \& Nersessian, 2016). Field-based differences in using regression analysis make economist assess ecologist as poor statisticians (Armsworth et al., 2009). Both groups of biologists, systemic and molecular, strongly disagree on the proper use of data and the explanatory role of simulations (MacLeod \& Nersessian, 2016). These are examples already studied in depth in the philosophical literature, but these are not the only examples, and the search for these differences seems to be extremely valuable and helpful in understanding both the prospects of improving cooperation in interdisciplinary research but also the character of individual disciplines (see: Wagenknecht, 2016). Although I could find no papers that would explicitly show the conflict between psychiatrists and psychologists regarding psychopathology, especially from the perspective of more practice-oriented philosophical studies or science studies (however, see: Peterson, 2016, 2017), these differences, I believe, are possible to find, and it is worth considering:

a. whether there are convergent attitudes towards data in psychologists vs. psychiatrists and others (case or cohort studies, experimental or correlative studies, studies on model animals and others);

b. what role theories and models play in psychology and psychiatry (what exactly is modeled by psychologists vs. psychiatrists?);

c. whether psychologists and psychiatrists share the same epistemic standards when assessing the correctness or reliability of research;

d. what kind of daily practices, routines or research habits are most epistemically valuable;

e. what differences in repertoires and research protocols between psychology and psychiatry are;

f. whether ethical problems, issues or challenges in both disciplines are the same. ${ }^{5}$

This can be summed up in one question: if we write biography of psychopathologies, will it be a more psychological — social-science-oriented biography, or psychiatry — more clinically, medicine-oriented biography? Even though there is no space for answering all the mentioned questions, and most of them still await the answer. However, as I say, I suspect that such answers will not be meaningless for Marcinów project.

We can search for these differences (and similarities) in the treatment of the subject and the manner of conducting research by psychologists, including experimental, correlation, clinical psychologists and psychiatrists, both scientific researchers and clinical practitioners or therapists.

\footnotetext{
${ }^{5}$ Exhaustive answers on the questions are beyond the scope of this paper, however, more detailed remarks on some of them will be presented in section 3 of this paper.
} 


\section{Disciplinary Hodgepodge and the Polish Psychopathology}

As I have already mentioned, Marcinów's work focused on the birth of Polish psychopathology also allows us to look at the emergence of Polish psychiatric and psychological research. ${ }^{6}$ The moment of emergence of psychopathology, both in the clinical and research context, gives us a unique opportunity to notice and track possible conflicts between psychiatric and pre-psychological works in psychopathology. Unfortunately, but maybe in accordance with her intentions, it seems that Marcinów's work blurs rather than highlights differences between these approaches.

Marcinów $(2017$, pp. 19, 39) emphasizes the psychological nature of her work. In other places, she underlines that her project requires precise tracking and "articulation of psychiatric narration with psychological referents" (2017, p. 17) However, as it should be evident from the above remarks, this is neither in any way obvious nor easy task. Additionally, referencing mental concepts presented in psychiatry as psychological by Marcinów is problematic. Does "psychological" mean here the nonphysical? Or maybe whatever entity singled out as part of psychological research? My reading of Historia... suggests the second answer. However, can we really say that melancholy as an object of psychology and as an object of psychiatry is the same object with one biography (see: Danziger, 1993, 2003)?

a. Marcinów describes psychopathological issues as psychological, not psychiatric. However, psychology as a scientific discipline was just born (naturally Marcinów is aware of this difficulty). Hence, it is difficult to describe the disciplinary framework of the investigated and discussed inquiries. This is the first problem.

b. When we look at the main theoretical part of Marcinów's book (2017, pp. 59176) and the source materials gathered in the second part of the book, her research seems closer to the searching approach for some issues related to psychiatry as a branch of medicine. Such assessment of Marcinów's work is also present in the review of her book contained in this volume (Zawiła-Niedzwiecki, 2019).

Naturally, to draw a distinction between psychology and psychiatry in the context that is of Marcinów's interest, is not an easy task. The nineteenth century is the age of the birth of psychology as a field of research. It's born in the works of e.g., Ribot, Wundt and with the James' classic textbook published at the end of the $19^{\text {th }}$ century. ${ }^{7}$ Psychology starts emancipating from both philosophical and medical studies of mental problems. But it is not necessary to talk about a full-blooded psychological approach of mental disorders. However,

\footnotetext{
${ }^{6}$ It is worth noting that it would be extremely valuable to embed the terminology development within the institutional development of both research and clinically-oriented work on the psychopathology of Polish research. Of course, this would be a difficult task, considering not only that psychology as a discipline was just emerging (in the second half of the $19^{\text {th }}$ century), which is clearly stated by the Marcinów (2017), but also the political situation - the lack of a Polish state.

${ }^{7}$ It could be very informative to know the reception, degree and way of acceptance of these psychological classics among Polish $19^{\text {th }}$-century psychopathologists.
} 
exposing links between the $19^{\text {th }}$ century approach to mental disorders with the remarks on formation of psychology as a discipline could be very informative, even for contemporary research. Hence, the basic problem of this book is the lack of a clear outline of what is, we can say, the differentia specifica of the emerging psychopathology as a psychological discipline. ${ }^{8}$ Moreover, in the initial part of Marcinów's work (2017), she points to a strong deposition of mental disorders in a cultural context, either by reference to Foucault's works on control and power or Hacking's study of transient disorders. I am convinced that a clearer sketch of the disciplinary distinctions could be useful in outlining the Polish dimension of psychopathology. It could help to outline the dimensions of Polish psychopathology. ${ }^{9}$

Psychopathology is a really interdisciplinary complex endeavor, and neglecting its interdisciplinary dimensions could lead to problems: we can miss terminological discrepancies (e.g., differences in use of some basic terms like "validity") or be simply misled by superficial agreements and apparent progress in research. The history of psychopathology could be, I believe, very helpful in identifying and tracking such discrepancies.

\section{Tracking through the Boundaries}

Philosophical and theoretical research on the methodology of clinical psychology, psychotherapy and psychotherapy, from the mid-twentieth century, was pioneered by Meehl (Cronbach \& Meehl, 1955; Dawes, Faust, \& Meehl, 1989) and his work is still of great importance. However, the current development of the discussed areas carries more challenges. For example, there are challenges brought about by $\mathrm{RDoC}^{10}$ in psychiatry, which is aimed to make psychiatry more research-driven (Insel et al., 2010; Insel, 2014), and related to this, an attempt to move from a binary account of mental disorders to a multidimensional one (Haslam, 2013). In psychology, the psychometric approach on psychopathology is gaining importance-whether it is network-based modeling of mental disorders, e.g., in terms of causal relations between symptoms (Borsboom, 2017), or searching for $p$-factors for psychopathology (van Bork, Epskamp, Rhemtulla, Borsboom, $\&$ van der Maas, 2017). Therefore, the image of psychopathology becomes even more complex. We can indicate here interdisciplinary issues related to psychopathology:

a. Meehl with collaborators (Dawes et al., 1989) describe differences between more intuition based—clinical and statistical—and psychometric based—actuarian-diagnoses.

\footnotetext{
${ }^{8}$ Marcinów's (2017) research is even more difficult when she starts to include in her investigation threats form the $19^{\text {th }}$ century literature. Her research probably needs a more transdisciplinary oriented treatment, see: (Brown, Harris, \& Russell, 2010; Koskinen \& Mäki, 2016). Marcinów attempts to integrate not only different academic disciplines, but also the relationship between the beginnings of scientific psychopathology and the various trails from the $19^{\text {th }}$ works of fiction and religious literature, etc. But here I leave this issue aside.

${ }^{9}$ By the way, it seems that another concept taken from looping effect studies would be useful in the Marcinów's endeavor. One could ask whether there is a specific Polish looping effect in the case of melancholy.

${ }^{10}$ For example, there is a controversy between a research-oriented-multidimensional—and clinically effective-one-dimensional - approach to mental disorders.
} 
Even they argue for superiority of the latter, without dismissing the earlier, however, completely. Further, in his autobiographic notes, Meehl describes the clash between a clinician and actuarian (see: Lindzey, Runyan, \& Association, 2007), and the complete dismissal of clinical methods (in his time, based on psychoanalysis) by actuarians. Naturally, these differences don't disappear, new ones emerge and problems intensify.

To some degree, the mentioned conflicts resemble tensions between the advocates of DSM-I and DSM-II and the advocates of DSM-III and later versions of the manual, and most likely between current supporters of DSM and supporters of RDoC (Keeley, 2014). However, this is mainly related to the conflict between clinical and research-oriented psychopathologists. This way, we can understand Bluhm calling for two ontologies: "an ontology for scientific research and a separate ontology should be developed to guide clinical practice. It may be that the explanatory ontology will inform clinical ontology, but there is no guarantee that this will be the case" (Bluhm, 2017). ${ }^{11}$

b. Sullivan $(2014,2017)$ notes that the key to research in psychiatry and psychopathology in general is to share protocols, standards or practices, which will lead to the stabilization and standardization of constructs that will be used in psychopathology. And when we notice that psychopathological research is interdisciplinary, "specific measures must be taken across different context of experimentation to ensure the stability of phenomena under study" (Sullivan, 2014, p. 258).

Sullivan (2014) analyzes in some detail a project focused on schizophrenia called "CENTRICS". This project looks for animal models of schizophrenia and integrates cognitive neuroscience with cognitive neurobiology. Therefore, Sullivan compares cognitive neuroscience - focused on task analysis, and trying to analyze specific mental functions, and cognitive neurobiology-focused on specific experimental paradigms, and investigating behavioral effects. What she says is even more intriguing: "[...] neither cognitive neuroscientist nor cognitive neurobiologist are specifically concerned with mental states of organism they study" (p. 270). Integration or even coordination of such research is not an easy task.

c. Another issue is related to recent initiatives to base psychopathology on searching on essential factor for it - so called $p$-factor. If successful, it could merge clinical judgment with the actuarian approach. However, in their recent paper (van Bork et al., 2017) find flaws of using such tools in psychopathology. They show that most conclusions in that research were not data-based but emerge as artifacts caused by tools used for analysis. We can suspect that different disciplines will use different tools for similar purposes.

d. Peterson $(2016,2017)$ conducted interesting ethnographic research on mind brain sciences [MBS]. Although it is not dedicated to psychopathology and interdisciplinary differences explicitly, it is extremely informative for my current investigation. In one of his papers, Peterson investigates the relation between broad and narrow research fields in MBS. He presents the clear lack of trust between stakeholders coming from fields of divergent

\footnotetext{
${ }^{11}$ In an interesting way, Haslam (2013) interprets DSM as an identification device. We can also try to identify DSM as being part of clinical ontology or something between these ontologies.
} 
scopes. Researchers discredit the problem choice, graininess of analysis, method choices and many more. These differences determine the results in different fields. Disciplines are considered without value because they are supposedly:

i. methodologically flawed and sloppy (in broad fields);

ii. precise but irrelevant (in narrow fields).

This kind of analysis can be easily transposed to psychopathological issues and divergent treatment of mental issues by molecular neurobiologists, clinical psychologists and phenomenologically inspired psychiatrists (see for example, debates on RDoC in 13(1)2004 issue of World Psychiatry).

e. With regard to the issue at hand, a non-surprising difference is related to the kind of validity found in psychiatry and psychology (Kendell \& Jablensky, 2003). While in psychology, we deal with constructs validity, in psychiatry, we are concentrated on diagnostic validity (Zachar \& Jablensky, 2014, p. 6). Haslam (2013) investigated a similar issue, i.e., relation between validity (relation between the measure and what is measured) and reliability (consistency in internal, interrater and intertemporal dimensions) in psychiatry (see also: Lefere, De Rouck, \& De Vreese, 2017). For example, phenomenological approaches are validity-centered, where $\mathrm{RDoC}$ is reliability-centered.

f. At the end we can mention that, in the context of Marcinów's project, there is an interesting issue of the role of case studies in psychiatry and psychology. More precisely, what value for psychologists do psychiatric presentations of individual cases of disorders have? Although the aim of the DSM and even more RDoC is to make psychopathological considerations more intersubjective, there is no doubt that the role of the case study for psychiatrists is not negligible. Possibly, this is the question of the role of clinical psychology and its methodology in psychopathological research.

The above-mentioned examples show that investigations in psychopathology can face many, in fact, interdisciplinary problems. The pluralism present in psychopathological research is still in need of coordination (Sullivan, 2017) and conceptual stabilization (Sullivan, 2014). Furthermore, these issues are accompanied by continuous questions of what type of kinds mental disorders are: pragmatic, transient, or diagnostic (Tabb, 2019)? There is no easy answer to this question. Therefore, quick merging psychological and psychiatric approaches can be more problematic than helpful.

Because of that, I believe that tracking the emergence of this type of differences - not only terminological ones - at the birth of Polish psychopathology would be helpful when noticed.

\section{Conclusion: On Appreciating Interdisciplinary of Psychiatry}

In the light of presented remarks, I want to draw conclusions. Despite the fact that Marcinów's project (2017) is extremely ambitious and rich, my main concern is that it neglects to mention obstacles to interdisciplinary cooperation, and ignoring them can lead to 
problems with the proper account of psychopathology, leaving unnoticed, superficial agreements, which will make research progress merely apparent. However, an appreciation of the complexity of interdisciplinary relations between psychology and psychiatry can help to expose not only psychopathology itself but also the Polish way of living melancholy.

\section{Acknowledgements}

The work on this paper was funded from National Science Centre re-search grant under the decision DEC-2014/14/E/HS1/00803. The author wishes to thank Marcin Miłkowski for his advice and invaluable support.

\section{References}

Ankeny, R. A., \& Leonelli, S. (2016). Repertoires: A post-Kuhnian perspective on scientific change and collaborative research. Studies in History and Philosophy of Science Part A, 60, 18-28. https://doi.org/10.1016/j.shpsa.2016.08.003

Armsworth, P. R., Gaston, K. J., Hanley, N. D., \& Ruffell, R. J. (2009). Contrasting approaches to statistical regression in ecology and economics. Journal of Applied Ecology, 46(2), 265-268. https://doi.org/10.1111/j.1365-2664.2009.01628.x

Berrios, G. E. (2008). Descriptive psychiatry and psychiatric nosology during the nineteenth century. In E. R. Wallace \& J. Gach (Eds.), History of Psychiatry and Medical Psychology (pp. 353-379). Boston, MA: Springer. https://doi.org/10.1007/978-0-387-34708-0_11

Berrios, G. E. (1984). Descriptive psychopathology: Conceptual and historical aspects. Psychological Medicine, 14(2), 303-313. https://doi.org/10.1017/S0033291700003573

Berrios, G. E. (1988). Melancholia and depression during the $19^{\text {th }}$ century: A conceptual history. The British Journal of Psychiatry, 153(3), 298-304. https://doi.org/10.1192/bjp.153.3.298

Berrios, G. E. (1996). The history of mental symptoms: Descriptive psychopathology since the nineteenth century. Cambridge, UK: Cambridge University Press. https://doi.org/10.1017/CBO9780511526725

Bluhm, R. (2017). The need for new ontologies in psychiatry. Philosophical Explorations, 20(2), 146-159. https://doi.org/10.1080/13869795.2017.1312498

Blustein, B. E. (1981). 'A Hollow Square of Psychological Science': American Neurologists and Psychiatrists in Conflict. Scull, Madhouses, Maddoctors, and Madmen, 241(270), 218-240. https://doi.org/10.9783/9781512806823-014

Boden, M. A. (1999). What is interdisciplinarity. In R. Cunningham (Ed.), Interdisciplinarity and the Organisation of Knowledge in Europe (pp. 13-23). Luxemburg: Office for Official Publications of the European Communities. 
Borsboom, D. (2017). A network theory of mental disorders. World Psychiatry, 16(1), 5-13. https://doi.org/10.1002/wps.20375

Borsboom, D., Kievit, R. A., Cervone, D., \& Hood, S. B. (2009). The two disciplines of scientific psychology, or: The disunity of psychology as a working hypothesis. In J. Valsiner, P. Molenaar, M. Lyra, N. Chaudhary (Eds.), Dynamic Process Methodology in the Social and Developmental Sciences. New York, NY: Springer. https://doi.org/10.1007/978-0-387-95922-1_4

Brock, A., Louw, J., \& van Hoorn, W. (Eds.). (2006). Rediscovering the history of psychology: Essays inspired by the work of Kurt Danziger. Boston, MA: Springer. https://doi.org/10.1007/b106634

Brown, V. A., Harris, J. A., \& Russell, J. Y. (Eds.). (2010). Tackling wicked problems through the transdisciplinary imagination. London, UK: Routledge. https://doi.org/10.4324/9781849776530

Campaner, R. (2014). Explanatory Pluralism in Psychiatry: What Are We Pluralists About, and Why? In M.C. Galavotti, D. Dieks, W. J. Gonzalez, S. Hartmann, T. Uebel, M. Weber, (Eds.), New directions in the philosophy of science (Vol. 5, pp. 87-103). Cham, Switzerland: Springer. https://doi.org/10.1007/978-3-319-04382-1_7

Clark, M. J. (1981). The rejection of psychological approaches to mental disorder in late nineteenthcentury British psychiatry. In A. T. Scull (Ed.), Madhouses, Mad-Doctors and Madmen (pp. 271-312). London, UK: Athlone Press. https://doi.org/10.9783/9781512806823-015

Cronbach, L. J. (1957). The two disciplines of scientific psychology. American Psychologist, 12(11), 671. https://doi.org/10.1037/h0043943

Cronbach, L. J., \& Meehl, P. E. (1955). Construct validity in psychological tests. Psychological Bulletin, 52(4), 281-302. https://doi.org/10.1037/h0040957

Danziger, K. (1993). Psychological objects, practice, and history. In H. V. Rappard, P. J. van Strien, L. P. Mos, \& W. J. Baker (Eds.), Annals of Theoretical Psychology (Vol. 8, pp. 15-47). Boston, MA: Springer. https://doi.org/10.1007/978-1-4615-2982-8_2

Danziger, K. (1994). Constructing the subject: Historical origins of psychological research. Cambridge, MA: Cambridge University Press.

Danziger, K. (2003). Where history, theory, and philosophy meet: The biography of psychological objects. In D. B. Hill, \& M. J. Kral (Eds.), About psychology: Essays at the crossroads of history, theory, and philosophy (pp. 19-33). Albany, NY: State University of New York Press.

Danziger, K. (2013). Psychology and its history. Theory \& Psychology, 23(6), 829-839. https://doi.org/10.1177/0959354313502746

Dawes, R. M., Faust, D., \& Meehl, P. E. (1989). Clinical versus actuarial judgment. Science, 243(4899), 1668-1674. https://doi.org/10.1126/science.2648573

Grüne-Yanoff, T. (2016). Interdisciplinary success without integration. European Journal for Philosophy of Science, 6(3), 343-360. https://doi.org/10.1007/s13194-016-0139-z

Haslam, N. (2013). Reliability, validity, and the mixed blessings of operationalism. In K. W. M. Fulford, M. Davies, G. Graham, J. Sadler, G. Stanghellini, \& T. Thornton (Eds.), Oxford Handbook of philosophy and psychiatry (pp. 987-1002). Oxford, UK: Oxford University Press. https://doi.org/10.1093/oxfordhb/9780199579563.013.0058 
Insel, T., Cuthbert, B., Garvey, M., Heinssen, R., Pine, D. S., Quinn, K., Stanislow, C., \& Wang, P. (2010). Research domain criteria (RDoC): Toward a new classification framework for research on mental disorders. The American Journal of Psychiatric, 167(7), 748-751. https://doi.org/10.1176/appi.ajp.2010.09091379

Insel, T. R. (2014). The NIMH research domain criteria (RDoC) project: precision medicine for psychiatry. American Journal of Psychiatry, 171(4), 395-397. https://doi.org/10.1176/appi.ajp.2014.14020138

Keeley, J. W. (2014). The background assumptions of measurement practices in psychological assessment and psychiatric diagnosis. In P. Zachar, D. S. Stoyanov, M. Aragona, \& A. Jablensky (Eds.), Alternative Perspectives on Psychiatric Validation: DSM, ICD, RDoC, and Beyond (pp. 94-111). Oxfrod, UK: Oxford University Press. https://doi.org/10.1093/med/9780199680733.003.0006

Kendell, R., \& Jablensky, A. (2003). Distinguishing between the validity and utility of psychiatric diagnoses. American Journal of Psychiatry, 160(1), 4-12.

https://doi.org/10.1176/appi.ajp.160.1.4

Klein, J. T. (2010). A Taxonomy of Interdisciplinarity. In R. Frodeman, J. T. Klein, \& C. Mitcham (Eds.), The Oxford Handbook of Interdisciplinarity (pp. 15-30). Oxford, UK: Oxford University Press.

Koskinen, I., \& Mäki, U. (2016). Extra-academic transdisciplinarity and scientific pluralism: What might they learn from one another? European Journal for Philosophy of Science, 6(3), 419-444. https://doi.org/10.1007/s13194-016-0141-5

Lefere, S., De Rouck, R., \& De Vreese, L. (2017). What to expect from reliability and validity claims? A pragmatic conception of psychiatric nosology. Journal of Evaluation in Clinical Practice, 23(5), 981-987. https://doi.org/10.1111/jep.12686

Leonelli, S., \& Ankeny, R. A. (2015). Repertoires: How to transform a project into a research community. BioScience, 65(7), 701-708. https://doi.org/10.1093/biosci/biv061

Lindzey, G., Runyan, W. M., \& Association, A. P. (2007). A History of Psychology in Autobiography (Vol. 9). Washington, DC: American Psychological Association. https://doi.org/10.1037/11571-000

MacLeod, M. (2018). What makes interdisciplinarity difficult? Some consequences of domain specificity in interdisciplinary practice. Synthese, 195(2), 697-720. https://doi.org/10.1007/s11229016-1236-4

MacLeod, M., \& Nagatsu, M. (2018). What does interdisciplinarity look like in practice: Mapping interdisciplinarity and its limits in the environmental sciences. Studies in History and Philosophy of Science Part A, 67, 74-84. https://doi.org/10.1016/j.shpsa.2018.01.001

MacLeod, M., \& Nersessian, N. J. (2016). Interdisciplinary problem-solving: emerging modes in integrative systems biology. European Journal for Philosophy of Science, 6(3), 401-418. https://doi.org/10.1007/s13194-016-0157-x

Marcinów, M. (2017). Historia polskiego szaleństwa: Słońce wśród czarnego nieba. Studium melancholii (T. I). Gdańsk, Poland: Fundacja Terytoria Książki.

Mora, G. (1970). The history of psychiatry: Its relevance for the psychiatrist. American Journal of Psychiatry, 126(7), 957-967. https://doi.org/10.1176/ajp.126.7.957 
Peterson, D. (2016). The baby factory: Difficult research objects, disciplinary standards, and the production of statistical significance. Socius, 2. https://doi.org/10.1177/2378023115625071

Peterson, D. (2017). The depth of fields: Managing focus in the epistemic subcultures of mind and brain science. Social Studies of Science, 47(1), 53-74. https://doi.org/10.1177/0306312716663047

Sierra, M., \& Berrios, G. E. (1997). Depersonalization: A conceptual history. History of Psychiatry, 8(30), 213-229. https://doi.org/10.1177/0957154X9700803002

Sullivan, J. (2014). Stabilizing Mental Disorders: Prospects and Problems. In J. Sullivan \& H. Kincaid (Eds.), Classifying Psychopathology: Mental Kinds and Natural Kinds (pp. 257-281). Cambridge, MA: MIT Press.

Sullivan, J. (2009). The multiplicity of experimental protocols: A challenge to reductionist and non-reductionist models of the unity of neuroscience. Synthese, 167(3), 511-539. https://doi.org/10.1007/s11229-008-9389-4

Sullivan, J. (2017). Coordinated pluralism as a means to facilitate integrative taxonomies of cognition. Philosophical Explorations, 20(2), 129-145. https://doi.org/10.1080/13869795.2017.1312497

Tabb, K. (2019). Philosophy of psychiatry after diagnostic kinds. Synthese, 196(6), 2177-2195. https://doi.org/10.1007/s11229-017-1659-6

van Bork, R., Epskamp, S., Rhemtulla, M., Borsboom, D., \& van der Maas, H. L. (2017). What is the p-factor of psychopathology? Some risks of general factor modeling. Theory \& Psychology, 27(6), 759-773. https://doi.org/10.1177/0959354317737185

van Bouwel, J. (2014). Pluralists about pluralism? Different versions of explanatory pluralism in psychiatry. In M. C. Galavotti, D. Dieks, W. J. Gonzalez, S. Hartmann, T. Uebel, M. Weber (Eds.), New directions in the philosophy of science (pp. 105-119). Cham, Switzerland: Springer. https://doi.org/10.1007/978-3-319-04382-1_8

Wagenknecht, S. (2016). A Social Epistemology of Research Groups. London, UK: Palgrave Macmillan. https://doi.org/10.1057/978-1-137-52410-2

Zachar, P. (2012). Progress and the calibration of scientific constructs: the role of comparative validity. In K. Kendler \& J. Parnas (Eds.), Philosophical Issues in Psychiatry II: Nosology (pp. 21-34). Oxford, UK: Oxford University Press. https://doi.org/10.1093/med/9780199642205.003.0005

Zachar, P., \& Jablensky, A. (2014). Introduction: The concept of validation in psychiatry and psychology. In P. Zachar, D. St. Stoyanov, M. Aragona, A. Jablensky (Eds.), Alternative Perspectives on Psychiatric Validation: DSM, ICD, RDoC, and Beyond (pp. 3-26). Oxford, UK: Oxford University Press. https://doi.org/10.1093/med/9780199680733.003.0001

The editorial and publishing process of this publication has been financed by the Ministry of Science and Higher Education from the funds for the dissemination of research (DUN) within the framework of publishing activity, contract no. 711/P-DUN/2019, period of implementation: the years 2019-2020. 